\title{
Joining the Backstage: Locality and Centrality in an Online Community
}

\author{
Wayne G. Lutters \\ Department of Information Systems \\ $\mathrm{UMBC}$ \\ 1000 Hilltop Circle \\ Baltimore, MD 21250 \\ lutters@umbc.edu
}

\author{
Mark S. Ackerman \\ School of Information and Department of \\ Electrical Engineering and Computer Science \\ University of Michigan \\ Ann Arbor, MI 48109 \\ ackerm@umich.edu
}

\section{Keywords}

Online communities, computer-mediated communication, social worlds, field study, fandom, Disney.

\begin{abstract}
The design of viable, small-scale community spaces on the Net is often a hit-or-miss affair. To better understand promising approaches in this design space, we go back in time to examine an earlier community technology. We present a field study of The Castle, a dialup bulletin board system, that focuses on Disneyland. As a "gathering place for Disney enthusiasts," The Castle is a fascinating, albeit eccentric, online community. The Castle's centrality in the fans' interest network allows it to function as a collecting point. Here people find similar enthusiasts and even those with insider knowledge. Yet, because of the cost structure of dialup access (an accidental side-effect of the technology), participants are overwhelmingly geographically local which had useful consequences for social maintenance. We argue that this geographical locality and centrality of interest allows The Castle to thrive. Most importantly, however, the combination of the two together creates a powerful social dynamic which has been lost in most contemporary online communities.
\end{abstract}

\section{INTRODUCTION}

As computer-mediated communication (CMC) technologies advanced throughout the Net era, both the public and the research literature embraced an overly optimistic vision of the globalizing potential of these technologies. The popular press became rife with stories of CMC systems, such as Usenet groups, chat rooms or MUDs, liberating individuals from their geographic constraints, allowing them to foster meaningful relations with strangers around the world. A classic, although early, example of this can be found in Rheingold (1993) where concerned Net-based conference participants in Tokyo, Sacramento and Austin provide late night emotional support for a father in Boston, whose daughter had suddenly fallen gravely ill. None have ever met face-to-face (p. 19). Although more muted, these globalization stories also proliferated in the research literature (e.g., Baym, 1997, p. 115).

The underlying message was the same for these stories: Online communities have the potential to radically transform social interaction and community formation. Collocation is no longer an essential ingredient for social cohesion; physical geography has become merely a burdensome constraint.

However, in our continuing investigation into how best to support online communities and their social worlds over time, we grew troubled by these one-sided portrayals. While, there is little doubt that such globalization has profound and valuable potential, earlier technologies reaped important benefits by being local. Could similarly limiting access also provide important benefits to CMCs in the Web era? What might restricting participants to a local area impart to an online community?

In this paper we study an online community using an older CMC technology, in order to focus on the effects of geographical locality. The first author spent three years as a participant observer on The Castle. (The name of the site has been changed.) Diversely populated and well attended, The Castle is 
also decidedly local in focus: The Castle is a dial-up bulletin board; non-local participants have to pay telephone toll charges to use it. By examining this earlier community technology, we gain the ability to examine the uses of geographical locality, something largely lost or discarded in the Web era.

The Castle is a fascinating, albeit eccentric, collectivity. As with many of the globalization examples, it too is a special interest community. The Castle is, in its own words, a "gathering place for Disney enthusiasts." Participants are deeply into Disney and Disneyland[1]; many appreciate having a place where they find people with similar intensities of interest. One participant, as part of her larger introduction to the community, reflected many of the membership's values.

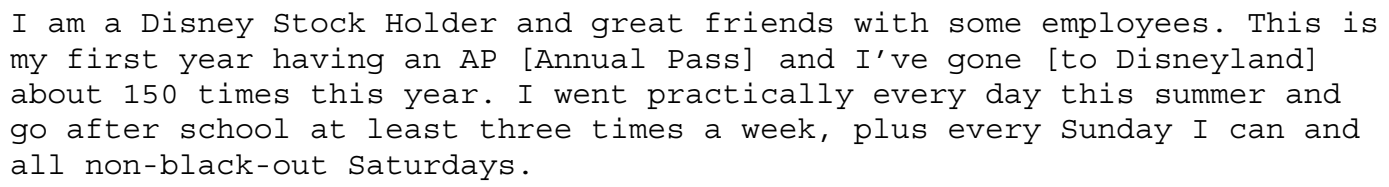

Participants in this online community are rabid about their interest - they know where to buy cigarettes in non-smoking Disneyland, when rides were installed (and modified), and where Walt Disney lived in Orange County. As we will see, this focus leads to a centrality of interest; that is, it creates a centrality (or concentration) within the specialized social network of people interested in Disney and Disneyland. For this study, this intensity and focus provides the opportunity to examine relationships between local rootedness, support for fandom and similar interests, and the capabilities of CMC technologies to expand one's social horizon in new and interesting ways.

Indeed, we believe that it is the very combination of geographical locality (henceforth, locality) and centrality of interest (henceforth, centrality) that allows The Castle to thrive. We found in this study that keeping participants local had three useful effects: staying focused, improved sensemaking, and fostering new real world interactions. We also found that The Castle's centrality in the fan's interest network led to several positive effects. Most interestingly, locality and centrality, put together, created a laudable, dynamic interaction, one worth emulating in Web-based systems.

The paper begins with a brief review of the literature concerning online communities and how they continue their social worlds over time. Following a description of the data, data collection, and analysis, an overview of the key social interactions at The Castle is presented. With this ground work laid, we then examine the effects of centrality within the participants' interest network as well as the effects of geographical locality. Finally, we address the additive effects of centrality and locality together.

\section{LITERATURE REVIEW}

There is a plethora of publications about CMCs. Historically, most were popular press articles that described $\mathrm{CMC}$ technologies, ranging from descriptions of dialup bulletin-board systems to Web-based systems (see, for example, the history of EXEC-PC for Wired Magazine in Rickard, 1993). Many of these describe why participants might join such online communities.

The $\mathrm{CMC}$ research literature itself is now quite broad, with a range of maturing research themes. (See Preece, 2000 for an excellent overview.) For example, a number of CMC studies investigate identity formation in CMC systems (e.g., Myers, 1987; Turkle, 1995). Others examine CMC use within organizations (e.g, Nickerson, 1994; Sproull and Kiesler, 1991; Orlikowski, 1992).

Of more salience here are the $\mathrm{CMC}$ research streams that examine sustaining participation over time in CMC systems, that examine locality in a CMC's use, and that examine CMCs for special interest groups. Relatively few studies track how a system is used over time and what conditions maintain its use. Correll (1995) offers an engaging ethnography of an electronic lesbian bar. She examines the formation of a core group of regulars. These regulars interact with lurkers [2] to maintain the community's boundaries, sustain the collectivity's norms, and train newcomers in these norms. Preece (1998) studied online patient-support groups, which had similar social structures. Preece also found that in even in medical support groups, participants desired a mix of relationships along with information exchange; they wanted 
a community of interest. Ackerman and Palen (1996) examined a discretionary synchronous message system at MIT. They considered what social structures and technical features enabled the system to continue being used over time. In line with Orlikowski, they demonstrated how individuals" "showing off" resonated with the institutional norms, providing critical individual incentives for continued use. While these findings informed our study, none of these studies, however, were focused on issues of locality.

On the other hand, "community networking" systems target the needs of a distinct, geographicallybased populace. (Please refer to Schuler (1996) for a comprehensive overview of these systems.) Classic examples of community networking efforts include the Santa Monica PEN system (Schmitz, 1997; Van Tassel, 1994), Berkeley's community memory program (Farrington and Pine, 1992), the Cleveland Freenet (Neff, 1995 in Schuler, 1996), and the Blacksburg Electronic Village (Carroll et al., 1996; Cohill and Kavanaugh, 2000). These CMC design projects have focused on garnering high levels of neighborhood or community participation. These community networking studies have shown the types of communication that spring from locality. However, they center on providing online support for existing, real-world organizations such as a neighborhood, church, social service or municipal constituency. In contrast, The Castle, is an affinity group without a real-world counterpart, merely an online gathering of Disney aficionados.

The final relevant $\mathrm{CMC}$ research stream is one that examines special interest online communities. One previously mentioned example is medical support (Preece, 1998). A number of fandom communities have also been studied (e.g., Lewis, 1992; Jenkins, 1992; Baym, 1997). These studies tend to focus on the particulars of a specific community. For example, Wexelblat (1997) examined the CMC support for fans of the science-fiction television series "Babylon 5." His study largely provided the details of Usenet use as well as noting the social and socialization effects of the CMC use. He also detailed the impact of active participation in the community by key individuals in the interest area, in this case the shows' creator. Similarly, Baym (1997) studied soap opera fans on Usenet. She found, as with other CMCs, the standard core of regular participants and the significance of building interpersonal relationships online. She discovered users personalizing summaries of soap operas and providing commentaries on storylines, thereby creatively participating in their fandom.[3]

In summary, there is a lack of CMC research which examines how systems successfully support local communities of interest over time. It is precisely this intersection of locality and centrality which is addressed by this study.

\section{THE CASTLE}

As mentioned, The Castle is, in its own words, "a gathering place for Disney enthusiasts." The Castle provides an electronic forum for anyone and everyone who would like to "tastefully discuss all things Disney," with a particular focus on the Disneyland amusement park.

The park is central to the online community's character. (One user enthused, "it just embodies everything I like about Disneyland and Disney.") The most overt influence is exhibited in The Castle's attempts to emulate Disneyland in the physical layout of the system. More subtly, the system has adopted the park's character - although it is a very warm, welcoming and entertaining environment, everything feels just a little too neat and orderly.

The centerpiece of this online community is its collection of conferences - participatory, topical, asynchronous message bases akin to Usenet newsgroups. The following series of excerpts from a message thread in the main conference provides an apt introduction to the quality and character of typical interactions. The thread was initiated and carried by a usual group of participants and focuses on a common topic.[4]

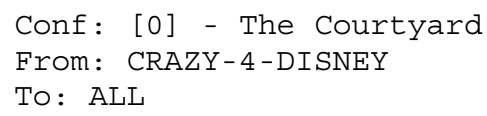




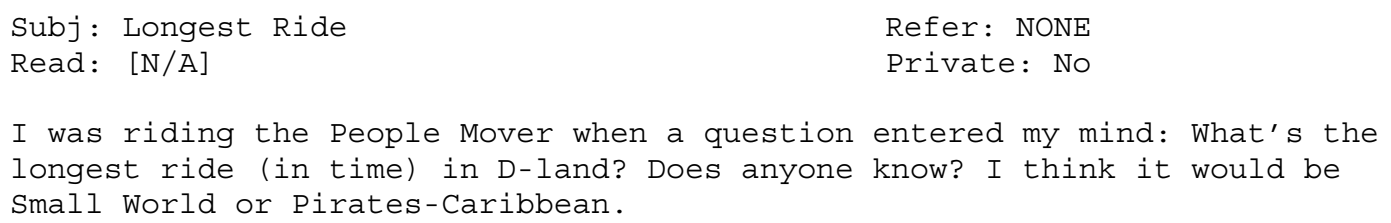

Other Castle participants responded. Below are three of eighteen responses:

(1) Hmmmm...are we counting Circle Vision? I think Pirates is $12+$ minutes. As I recall, it took us 3 and $1 / 2$ hours to ride 11 times in succession last year at the Pirates $5 \mathrm{~K}$ Charity Ball. Does anyone remember that???? Actually, Skyway just checked this out and I think Splash Mountain is the longest by about a minute or so over Pirates. Skyway and some guy he knew from UCLA had a good time funnin' me about the scarefactor of a 50-foot drop. We walked by a sign and I said, "See? It says 'You may get wet,' not 'You may die.'" Anyway, it had been forever since I'd been on it and it was great fun. And there's no "may" about it--we got plenty wet!

(2) Arial, I finally rode Indy too. It was 12:45 am and the line didn't start until inside the building so we only had to wait about 20 minutes. Yes, that is SOME ride! I was in the back right-hand side with no one next to me. I got bounced all over the place and was holding on with both hands. That snake snapped right at me! (He gets really close!) Actually, it's the Disneyland Railroad - but the next longest is a close second Pirates of the Caribbean.

(3) It's definitely gotta be the Disneyland Railroad when Engineer Fred is running the engine. He's so slo000000000wwwwww that you fall asleep when (if) the train is moving!

As is typical with topical threads, there were a number of tangential branches in addition to the continuing central topic. One such branch revolved around sharing tips on when the lines would be shortest to ride Indiana Jones ("Indy"), Disneyland's latest adventure ride. Another branch was a sidediscussion by a number of Disneyland employees ("cast members") about planning that year's 5K charity "run," where participants raise money by riding a particular park attraction for that distance.

This is representative of discussions at The Castle. While topics may vary from obscure trivia to the morning's news (about Disney of course), the content is engaging and locally relevant. Such diverse participation is also common, with discussions involving many participants. Long threads involving only two participants are rare, and very few questions go unanswered.

Before examining the roles of locality and centrality at The Castle, we need to provide a deeper understanding of the general social world of this online community. This background will assist in later discussions of the behavior observed. The following four sections describe the study itself as well as The Castle's participants, typical behavior, and special characteristics that mark it as a distinctive social world.

\section{Methodology}

Data collection for this study consisted primarily of extended participant observation and analysis of the message logs. These data were supplemented with interviews with regular participants, posted bulletins and newsletters, and monthly membership lists. The first author also attended one of The Castle's "in real life" events, meeting fifty of the system's participants face-to-face.

Examination of the message logs began at the invitation of central participants. These logs became the focus of our analysis. The data presented here are principally from a one-year time span: August, 1995 through August, 1996.[5] The analysis followed standard qualitative techniques used to examine smallscale interactions (as in Strauss, 1987; Strauss and Corbin, 1990). 
We used the other data to guide and confirm our analysis of the message archives. Of primary interest here were the semi-structured interviews (Lofland and Lofland, 1984) with seven of the twentyeight core participants, including two system operators ("sysops").

\section{Basic Functionality}

The Castle is a classic hobbyist bulletin board system (BBS). It was founded and run by a small coterie of friends out of one of their homes, and has been in continuous operation for over six years. It is both free and public.

The Castle is built on the WildCat! 5.0 code base, one of the most popular hobbyist BBS systems of the early 1990's. The Castle is heavily modified from the standard WildCat! defaults (enabling features such as pseudo-anonymity, and disabling features such as private chat, automated statistics and full user listings). It is also lavishly decorated with clever ASCII art, Disney quotations, and trivia. Although it started out with two phone lines, thus enabling synchronous multi-user interaction, by 1996 it had limited itself to a single line. The Castle does not support any of the common client-server graphical front ends (e.g. RIP), thus all interaction is done in simple ASCII text.

On the majority of dial-up bulletin board systems, the most popular activities, bar none, are file exchanges among participants. Traditionally this consumes most of the systems' resources and accounts for the majority of login time. However, this is not the case at The Castle. The sysops' insistence on having only legal, licensed, Disney themed software led to file exchange being an integral but minor aspect of interaction at The Castle. Pseudo-interactive gaming is a similar situation, popular on most bulletin board systems, yet almost non-existent at The Castle.

As mentioned, the central functionality of The Castle is its asynchronous messaging. The introduction for new users aptly explains, "[T] he very foundation of The Castle is our message base." This message base is a collection of moderated, topical conferences which contain both messages posted publicly, as in a newsgroup, and sent privately, as with e-mail. The main, general-interest conference is "The Courtyard." Besides this general-interest conference, other conference topics include Disney film trivia, Disney owned sports teams, employment opportunities, current news about the theme parks, and classifieds for Disney collectibles. Because of The Courtyard's wide audience and role as a central meeting place, our subsequent analysis will focus on interactions within The Courtyard.

\section{The Castle's Population}

During the study, The Castle had at least 350 active participants [6] at any given time and averaged 362 logins per week. It entertained an aggregate membership of 752 different individuals. This population was highly mobile: of the $752,53 \%$ left the online community during the study interval, $23 \%$ were newcomers and $24 \%$ consistently remained participants. Nonetheless, there existed a stable core of about thirty users at The Castle.[7] The key attributes of this sub-population were long-term use (many having been with the online community since its inception), moderate to heavy posting behavior, and participation in "real world" meetings and events. There were also significant sub-communities of lurkers and transients, including a sizeable group of long-term, frequently attending lurkers.

During the study interval, The Castle had a significant decline in membership, from 582 at the start to 351 at its conclusion. However, much of the loss was in its transient population; The Castle lost only one core participant during this period. On follow-up visits, up to a year after the study interval, the online community had stabilized at approximately 320 active participants.

As described, the most integral social activity at The Castle is message posting. During the interval, the board experienced a mean of 153.9 messages posted per week (45\% public, $55 \%$ private) across all conferences. The Courtyard had 74 postings per week, with $29 \%$ of them public.

When compared to login rates and active membership counts, the posting behavior is relatively light. Nearly $65 \%$ of the active participants post less than ten messages annually. Participation is also limited with a total of 151 different people posting messages to the top five conferences during this 
interval. Yet, of those who posted messages a full $49 \%$ were from those who remained active participants during the full study interval.

\section{The Castle As a Social World}

The atmosphere of The Castle is distinctive. While The Castle's participants are participants in many other diverse communities, The Castle is a social world with its own language, social understandings, norms, and rituals (Cressey, 1932; Becker, 1982; Maines, 1991; Strauss, 1991). We will describe here only those characteristics that are key to understanding how the community maintains itself socially. Therefore, we discuss three defining characteristics: the effects from asynchronous communication, pseudo-anonymity, and their tightly focused and restrained discussion.

Communication in the conferences at The Castle is very asynchronous, with reply times varying from a few hours up to two weeks. The cadence is slow. The medium is also low-bandwidth with text not longer than a screen length being standard. While we described the basic interaction previously, the cadence and rhythm of The Castle are very important to understand.

The excerpt (reformatted to fit this page) and description given below are typical of the pace of interaction. The exchange begins with the participant publicly posting her plans for her son's first trip to Disneyland:

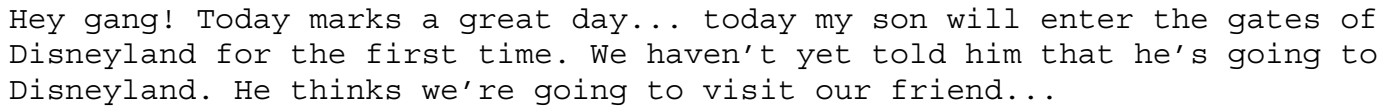

Her post is followed four hours later by another parent describing her child's first trip to the park and offering some pointers. Over the next two days there is only one additional reply. After the big event she posts a blow-by-blow description of the day which garners one brief congratulatory reply. She does not publicly post again for the next three weeks, although she is one of the top twenty-five message posters on the system.

Average response times tend to be in the space of a few days, with notable exceptions in both directions, being answered in a few hours and taking over a month. The usual expectation limit appears to be a week for most communication. Following are responses from "Tiki Bird" to two other participants (one of whom is a sysop) regarding their tardy answers to her trivia question:

(1) Sorry, but a few days late. The answer was revealed a few days ago.

(2) Wow, you're real late. The answer was put on days ago.

In addition to the slow pace, all interaction is pseudo-anonymous. In keeping with the themed nature of the system, everyone must assume the unique alias of a Disney character when they apply for membership. The ensuing pseudo-anonymity is complete - no other individual level information is available about users (a reaction to this is the introduction ritual which will be discussed later).

As the alias is the only form of personal identification on the system, it carries great significance. People choose their names with care. Popular names are often hot commodities. If a preferred name is already taken users will often select phonetic variations on the name ("Mighty Dux" or "Winnie da Pooh"), humorous interpretations ("Cruella Devil" for "Cruella Deville") or creative extensions ("Anaheim Mouse"). Simba, the main character from the animated feature "The Lion King" and a popular alias, is often unavailable. As a result some creative alternatives have been "Young Simba," "King Simba" and the more outlandish "Simba *ROAWWR!*". The use of aliases often leads to conflicts and confusion among users, one of the few tangible tensions on The Castle.[8]

A well chosen alias is not only a desirable personal identity marker, but also a symbol of enthusiast or insider status. Some of the most celebrated handles are either the result of obscure trivia (an animator's nickname for an un-named character which appears for a matter of seconds in Fantasia) or employee status ("Bus Driver," "Sweeper," "Imagineer"). Users enjoy this: 
I agree that it is kind of interesting to try and discover the tie to

Disney on some of the less obvious names.

On The Castle, pseudo-anonymity is viewed as essential in protecting its members. According to the participants, the Disney corporation is very strict about what its employees can and cannot discuss in a public forum, even when they are off duty. It is common belief that corporate officials regularly visit The Castle to check on the information being discussed. One core participant's advice to a questioning new user was:

The leads or managers employed at factions of the Walt Disney Company regularly lurk here. Claiming to be an official spokesperson of above factions could conceivably get one in trouble or fired unless they were indeed an ambassador.

There are stories of participants being called before management, shown a stack of printouts, and asked to justify themselves. The pseudo-anonymous handles and frequent disclaimer tags on messages appear to assuage this fear and loosen up the communication.

In spite of the obstacles of slow cadence and forced anonymity, The Castle manages to maintain a positive and focused environment. Indeed, conversation at The Castle is remarkably focused. Here participants are carefully guarded against wandering off topic, always conversing about "all things Disney." Tangents not relating to Disney are exceptionally rare.[9] The sysops and a small core of dedicated users appear to be responsible for the successful transmission of these social norms.[10] Discussion of what is acceptable and what is not rarely occurs in public, however, here a core participant responds publicly to a private inquiry about the system's degree of focus:

(1) BTW (asking in a serious manner) Do all comments and questions have to be Disney related or have mention of same, in each msg? I'm wondering...

(2) Well, yes, it's 'sposed to be - after all, who's the leader of the club that's made for you and me? M-I-C-K-E-Y M-O-U-S-eeeeeeeeeeeeee!!!!!

Another long-term user offered some advice to a relatively new user that his public posting thread had become too personal to be of public interest:

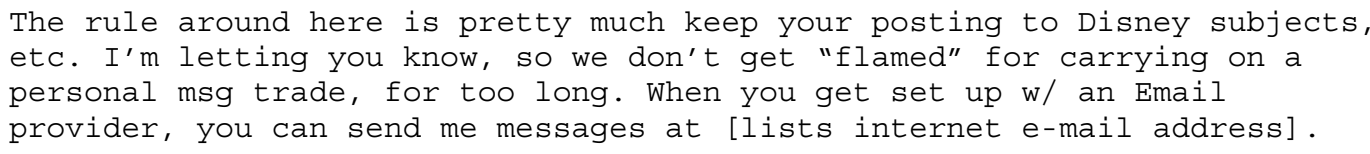

Not only are the conversations topically focused, but the interaction is also civil and guarded in the same manner as interactions are at a Disney theme park. Flaming, so frequently a component of CMC's, is relatively non-existent at The Castle.

Language and message content is controlled to keep The Castle an appropriate venue for users of all ages. In the following excerpt a participant replies to another:

(1) Darn! (can I say that on here?)

(2) Now [sic] remember there could be children here on the Castle

This focus and civility is achieved not only through the community's self policing. It is also due to the active involvement of The Castle's central sysop. A fellow sysop commented on this:

"I'll have to give [him] credit for this one. His whole idea in starting The Castle was so that people would have a place to talk about Disney. The Castle is not a social club. It's not a single's bar. It's strictly a place for Disney fans/critics to talk about Disney. When things start to stray, [he] usually brings people back into focus, which sometimes includes deleting messages."

A core participant noted this as well, addressing an even more severe behavior: 
"I think they [participants] know darn well that if they get a little out of hand then he will just kind of tell them 'hey.' And he has done that in the past... it just goes off topic and drags on, kind of like beating a dead horse, and he finally just puts an end to it saying 'hey, that's enough.' You don't have much riff raff on there... I think most of the time what happens is the moment he sees anything on there he just deletes the user right away."

This type of control is accepted by those participants who remain active in the community. A particular situation, in which a troublesome participant posted a listing of the top ten ways to upset Disneyland security personnel, demonstrated this. Many participants individually admonished the troublesome poster, the sysop deleted the offensive message and publicly posted a firm and lengthy rebuke, briefly excerpted below:

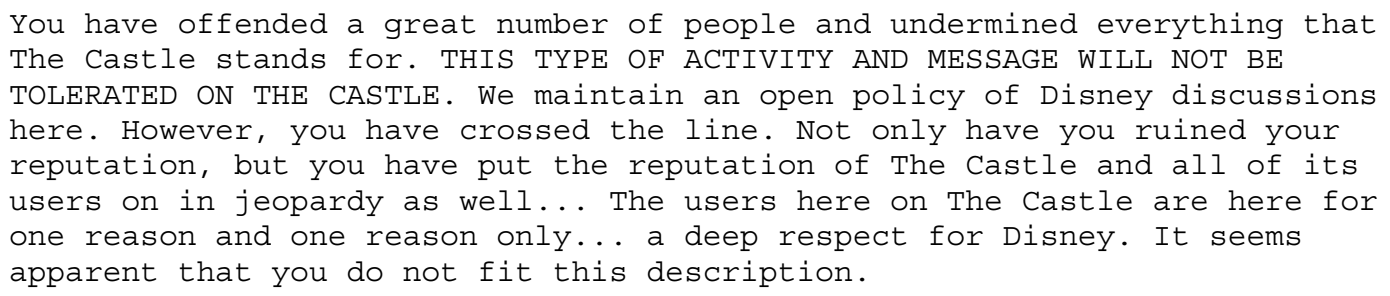

Indeed, the sysop mentioned that the troublesome participant had brought discredit to the entire online community in Disney's eyes. No Castle participant disputed this position and the user did not reappear in the usage logs afterwards.

While there are many additional attributes in the interactions at The Castle, the aforementioned three are the most prominent and provide the necessary background for understanding this online community. Next we progress to an examination of centrality and locality at The Castle.

\section{SOCIAL MAINTENANCE AT THE CASTLE}

In order to sustain themselves over time, online communities such as The Castle must maintain relatively stable role, norm, and incentive structures. Of particular interest here are the advantages accruing to its membership. Since an online community is almost always a voluntary association, its participants will remain active only while they are achieving personal rewards or benefits.

The Castle has sustained itself as a successful online gathering place in this very way - by maintaining a stable social structure with direct benefits for its membership. As a dial-up bulletin board, The Castle can capitalize on the advantages of being geographically local as well as providing a focal point for its members' concentrated interests. This centrality within each participant's interest network (about Disney) and locality within their physical space (in southern California) are essential to this community's ability to maintain itself socially over time. The two in conjunction are a powerful reinforcement to the online community. Centrality provides benefits for information seeking, expertise, and assistance. Locality provides a degree of geographic fixedness, establishes boundaries, provides a common frame of reference for discussion, keeps information locally relevant, and facilitates group activity in the real world. Each is discussed in turn below.

\section{Centrality}

The Castle serves as a hub for each participant's fascination with Disney and Disneyland. There are various facets to this centrality - general interest about Disneyland, the ability to garner expertise that might not be available easily elsewhere, and access to others interested similarly. Each facet will be addressed individually.

\section{Centrality in the Interest Network}


As described above, participants at The Castle remain uncannily focused on "all things Disney." As a newcomer to the system this devotion can strike one as eerily extreme. While all fan communities tend to focus in their interactions, it is important to note the depth and intensity of the focus at The Castle.

Most participants view themselves as "enthusiasts" and "fans" (in their own terms), particularly of Disneyland and its related products. For many, they have been Disney aficionados for most of their lives.[11] Many are currently, or have been, Disney employees themselves. Others are long-term annual pass holders, visiting Disneyland at any opportunity they can find. For example, one participant casually commented in a thread on dress code at the park:

During the forty days I stopped by after work each day... [emphasis added]

Another core participant mentioned in his interview that when he had clients in Orange County he would stop by the park every day after work to wait for the traffic to clear before heading home. He kept this up for over a year. Still others would attend only to see a particular artist, eat at a restaurant, or simply walk the park for exercise.

Just as theme park attendance for this community is well above average, so is their interest. Beyond an avid concern with reference trivia, there is a driving motivation for personal, "backstage" experience. They have a desire to know Disneyland much more deeply than other visitors. Discussions about behindthe-scenes activity at the park are a mainstay of the conferences, ranging from architecture to events to restaurant and shop reviews. Any minor alteration in the park, from a new flagpole to a water fountain, is duly noted in extended threads. Highlighting this, one participant posts about some subtle upgrades to a new ride (note the reference to the specific car):

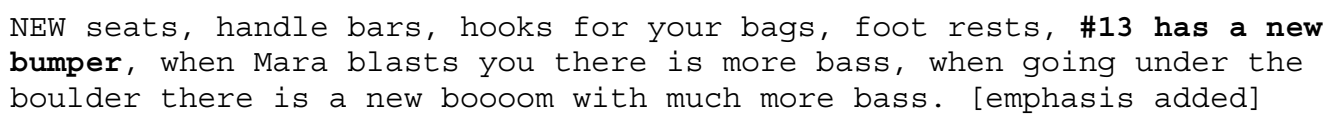

Another fine example of this is the quest for "hidden Mickeys" (subtle architectural elements in buildings resembling the familiar Mickey Mouse emblem - impressions in cement, splashes of paint, engravings in wood posts, etc.). The Castle's enthusiasts deeply desire this insider knowledge:

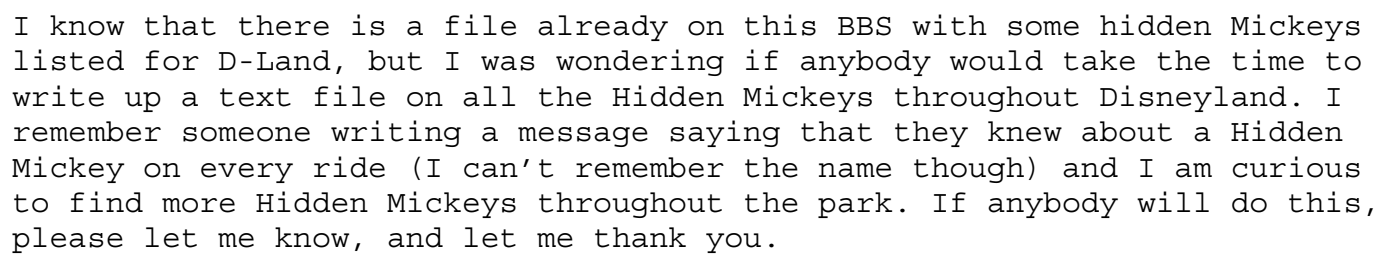

A final illustration is from an extended thread describing the clandestine smoking culture at officially non-smoking Disneyland (ostensibly for employees and foreign guests). In it a core participant boasts that he is aware of all the available points of sale. Although he himself is a non-smoker, he purchases cigarettes for their accompanying collectible matchbooks:

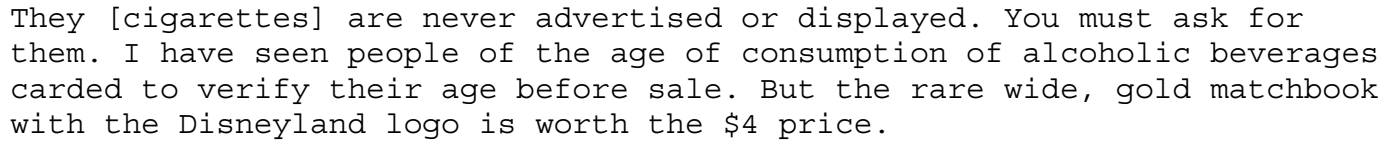

This extreme interest in both attending the park and knowing as much as possible about it fosters a strong sense of group identity at The Castle. Almost all share a similar fervor and one's group and individual identity as a "Disney enthusiast" is reinforced by the interactions. Indeed, just being a member at The Castle provides a means of authenticating one's self as a fan. In an interview, "Dutchess" highlighted this as follows,

“There's an identity and I guess it allows me a certain vicarious identity as a Disney enthusiast. I sign-on, ergo, I am a Disney enthusiast. You know what I'm saying? ... I've 
learned more on that board than I ever dreamed [sic] existed. Which makes me a very interesting conversationalist at parties..."

Another long-term participant commented on how much he appreciated the "intimate details" that he could find only at The Castle,

"Whereas the Usenet group, that alt.disney.disneyland Usenet group, a lot of it is people asking questions... They throw answers out, these people who have been to Disneyland once and they don't really know, but The Castle I mean they get a lot of people that are there, a lot of people on that board work there at Disneyland too. A lot of them are cast members."

An example of a public display of this Castle-endowed enthusiast identity off-line are the King's Challenge buttons. These are elaborate buttons that are made for The Castle's annual Disneyland gathering. Attendees save these badges from previous gatherings as collectibles. Many wear them regularly throughout the year, taking great pride in displaying them around the park, fielding questions from curious tourists and park aficionados alike.

\section{Centrality of Expertise}

In service to these interests, The Castle functions not only as a place to exchange information about Disney, but also to engage expertise. Expertise at The Castle is measured primarily by one's insider knowledge of Disneyland itself and secondarily that of Disney in general. One participant wrote:

My favorite part of Disneyland is the backstage information and stories, trivia and legends. I can't get enough!

The Castle is a rich resource in her pursuit of Disneyland details. It is established as a place where experts gather. This is one of its primary attractions for both recent recruits and established participants. The information which these experts provide is deemed to be of very high quality. One member enthused:

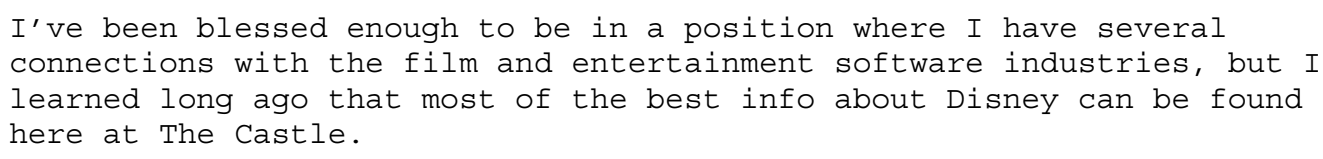

All participants benefit from the fact that The Castle brings together exceptional Disney enthusiasts. Many members have had a long association with the park, providing richness and depth to discussions. Participants frequently discuss such insider topics as annual pass programs, the company club, parking problems, local restaurants, and best times to visit the park. In general, extended experience with the park is valued as highly as mastery of general Disney trivia in this fan community. This experience is not limited to consumers but extends also to past and present employees. (Disneyland patrons and Disney employees are not distinct groups - enthusiasts often desire to be seen as employees, and employees are often enthusiasts, albeit somewhat jaded enthusiasts.)

Current employees bring a wealth of knowledge and minutia. As one example, one low-level employee posted the plans for the annual Halloween party at Disneyland:

This just in: Halloween has changed AGAIN! This information is from the Disneyland Line and our dept. heads.

In this message, the employee proceeds to describe extensive details about this popular seasonal event. Much discussion ensues and a fellow employee follows up two weeks later with insider tips for securing the elusive tickets for this traditionally sold-out event:

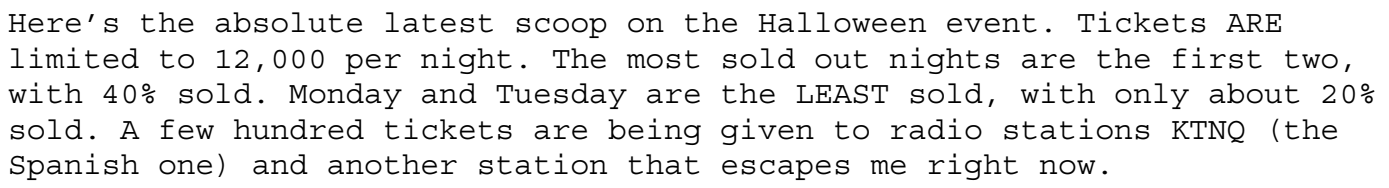


Similar updates of insider information are a regular occurrence for all of the special park events (parades, holiday shows, themed nights) and local Disney activities (film premieres, stage shows, entertainment centers). There are detailed, often lengthy, discussions of rumor and fact surrounding the park's plans. Disneyland expansion plans and parade modification details, for example, were announced first by insiders and then hotly debated by core participants. Indeed, there are even detailed conversations about topics specific to Disneyland employees, such as parking or benefits, which are engaged by the entire community.

Regarding the veracity of answers to questions, a significant Castle sub-population of current and prior employees are highly qualified experts. One particularly illustrative example involved a debate over a minor architectural alteration to a building at Disneyland for a holiday celebration. A few messages had been volleyed when one participant gave a definitive response, closing with "I should know... I helped build it." Such authoritative comments are not uncommon on The Castle.

Quality and accuracy of the information provided is a highly held cultural value at The Castle. Requests for information are usually met with more than one response. Participants will frequently correct, comment on, or elaborate each other's responses.

\section{Centrality of Access}

The Castle is not only an active repository of expertise, it also serves to provide social connections. Notable examples of this networking involve requests for insider employment information and assistance. In the following message, a participant petitions others for information about the audition process for the themed parades at the park:

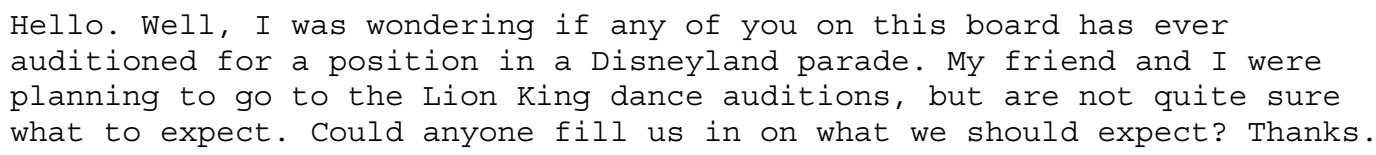

He receives two responses from participants who have both gone through the audition process themselves and offer full descriptions of the process, personal commentary (one found it very stressful and the other remembered it as one of the most enjoyable days of his life), and helpful tips. There were numerous other, similar message threads with participants asking about employment, age requirements, and work experiences in the different divisions.

A second message moves beyond a request for insider information to a personal request for insider assistance.

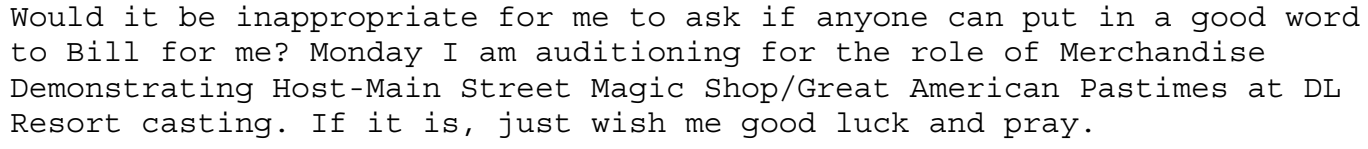

This abundant networking was confirmed in our interviews. In one particular case a core participant described how she had met an older Disney employee who became her mentor, providing direction through college and insight about careers in the amusement park industry.

A less obvious, but no less valued, benefit from these new social connections is the opportunity to be "signed in" by a cast member. An employee perk, cast members are allowed to offer a certain number of registered guests free admission to Disneyland. In addition to entering the park for free, there is the honor of being an invited guest of an employee, which includes the use of the separate employee entrance and the ability to go behind the scenes (escorted, of course). One participant pridefully divulged in an interview that this has been a privilege he has enjoyed both in the past, "I went in over a year and a half period about 32 times all on the employee privileges of friends of mine, in fact, I haven't paid to get in for about eleven years." and present "yeah, it's Mother's day, a friend of mine is signing us in, like I say, I don't pay to get in." 
In summary, the various forms of centrality provide incentives for fans to continue to come to The Castle over time. The next section shows how locality plans an integral role for the participants as well.

\section{Locality}

The Castle is a geographically localized system. The technology indirectly constrains the geographic diversity of its membership by the simple virtue of long distance telephone charges. Simply put, the primary barrier to entry is that people are more likely to become involved at The Castle if it is a free local telephone call than they are if it is an expensive (especially out of state) toll call. As a result a high percentage of participants live in the local vicinity of Disneyland.[12] This leads to specific effects from localization, which we will discuss in turn.

It is important to note that the physical location of the system supporting this online community lends it credibility in the eyes of its membership. One core participant expressed this eloquently, "When I first signed on to it the fact that it was Anaheim kind of implied a certain legitimacy... I think its locality lends to its intimacy... The Castle is like a local gathering place."

Locality of Focus

Local topics include not only Disneyland itself and its consumables (since consumption is a primary theme and motivation for Disney enthusiasts), but also local events related to Disney. As mentioned The Castle is dedicated to discussing "all things Disney," which frequently includes topics outside the sphere of Disneyland, but there is a strong tendency to view even these issues through local lenses. For example, high-level corporate issues are a very minor, almost non-existent, conversation thread in the Courtyard. However, whenever the annual meeting is being held in Anaheim or Burbank it tends percolate to the foreground. In the following excerpts from an extended thread, the primary debate is not about the shareholder referendums on the ballot that year, but whether or not meeting attendance comes with a free day pass to the park:

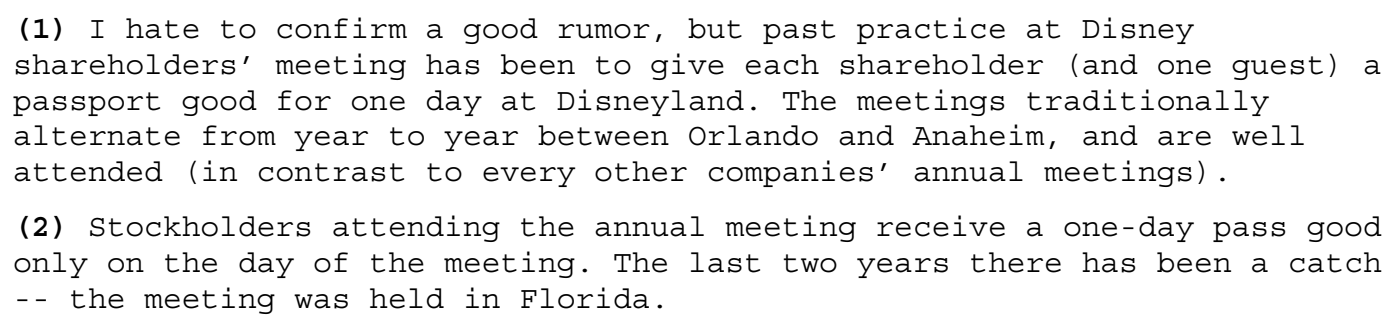

In the same fashion, Disneyland is often used as a focal point for describing other local issues. Rides are compared between amusement parks. Special events are compared and contrasted (notably themed events for Halloween and Christmas). In the following example a participant provides an extensive (multi-page) price comparison between two popular Southern California attractions and Disneyland:

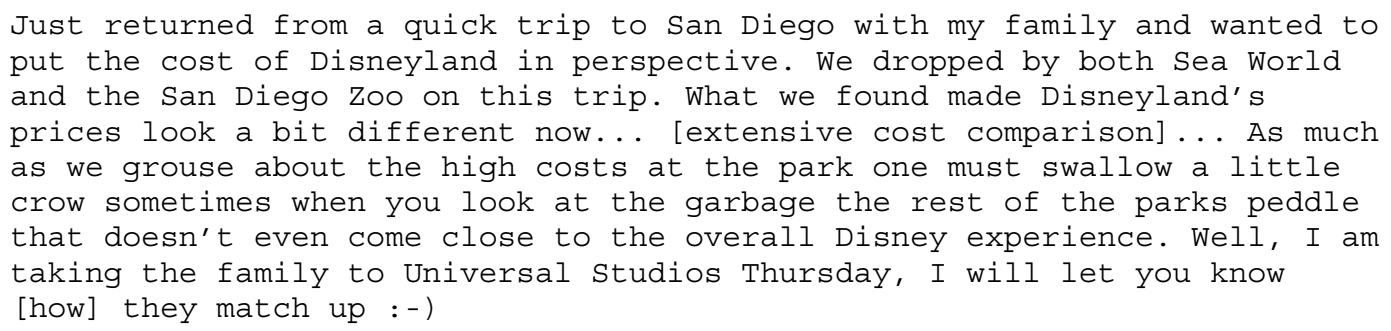

Trip reports are another illustrative example of the tendency to describe non-local artifacts and events with a local perspective. Participants often travel to Walt Disney World in Florida or to Disney's international theme parks, and post lengthy trip reports when they return. These commentaries are almost exclusively comparative descriptions, comparing and contrasting the park they visited with Disneyland. An excerpt from a typical Walt Disney World report follows (with descriptions): 


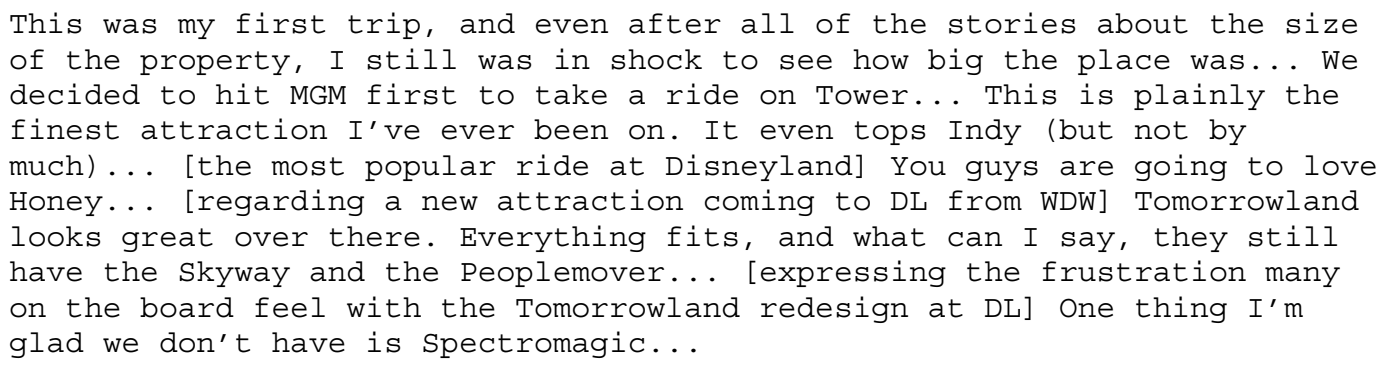

Another message excerpt clearly shows the comparison of the parks:

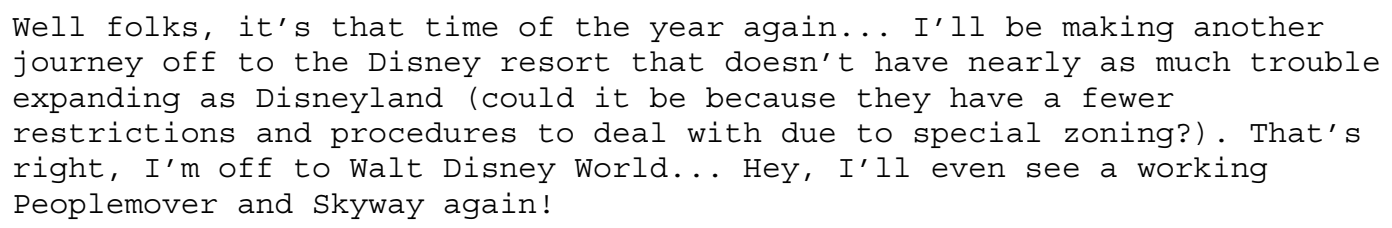

Thus, as one participant noted, "if you look at the board it is primarily a board about the park." We have noted that that discussions at The Castle center on the Disneyland park, but also expand to include other Disney and theme park news when appropriately filtered through a localizing lens.[13]

\section{Locality of Reference}

Information provided at The Castle is locally relevant to its participants. Having so many members living in greater Orange County, the local environment forms the basis for a shared context in their conversations. As one sysop commented, "there's a sense of knowing people better just because you have a similar environment." This frequently includes such topics as local traffic patterns, the best parking lots, crowd levels at the park, ride maintenance schedules, as well as area restaurants, attractions, and non-park Disney events (e.g. memorabilia sales, fan conventions, movie premieres, or opening nights for theater productions). In our first example, a participant requests information about local parking:

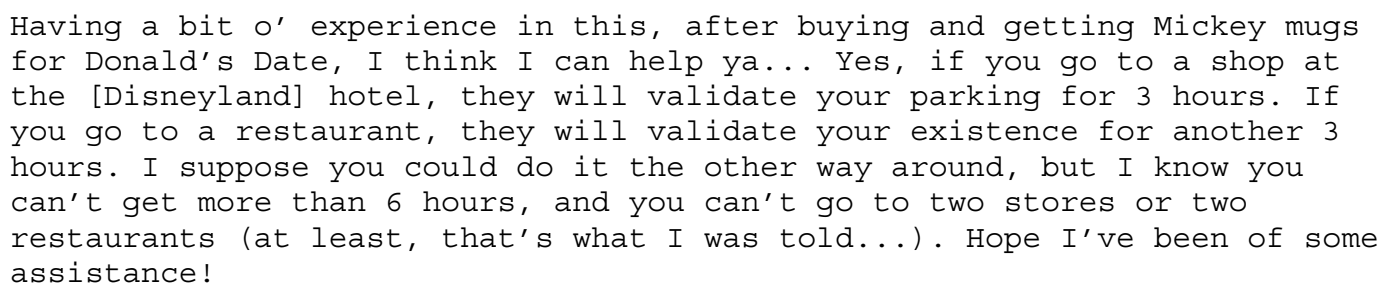

The next example is from the conclusion of a recurring multi-year thread regarding pedestrian crossing conditions on the major road in front of the park. Note how this information is extended to be of relevance to cast members. (Harbor is one of the two major surface streets adjacent to the park.)

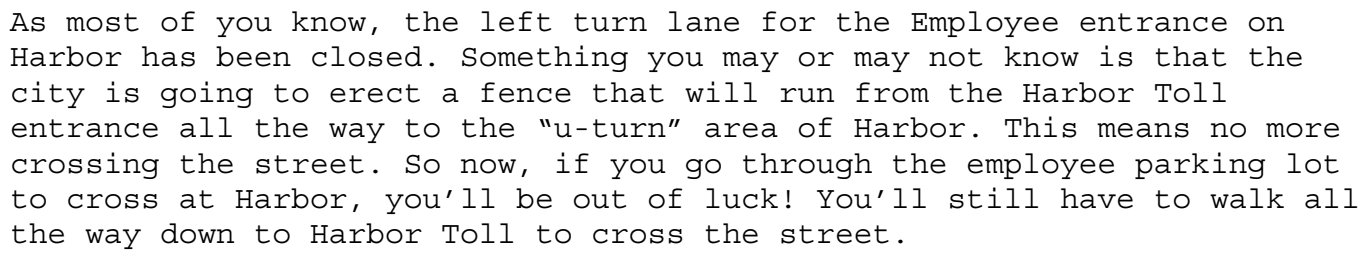

Information is largely provided for the local Anaheim area. In another thread, a frequent ice skater posts extensive schedule and pricing information for Disneyland's ice-skating rink, followed by the same details for alternate rinks in the city:

\footnotetext{
Here are the times and prices for the ice skating at the hotel, also I have included info for the other ice rinks in Anaheim.
} 
Participants are also quick to point out local resources that may be helpful in answering another's question. Often this may be an article in the Los Angeles Times or the Orange County Register (the two largest daily newspapers for the region), a book or magazine (along with a tip on which bookstore has the best price), government agency, or independent information source. In the following post a participant directly answers a question about off-season park hours (information readily available in the bulletin section of the system), but also offers a local telephone hot-line for future reference:

According to the recorded info line (555-9999), the current operating hours for the weekdays are 9-6 instead of the normal 10-6.

The final example involves a participant who is frustrated trying to procure a copy of a recently released limited-edition Disney videotape. Without any reference to his whereabouts, certainly an ambiguous attribute in cyberspace, participants offer relevant local options. All of these references are to stores and shopping areas in the Disneyland vicinity:

(1) My Albertsons no longer has the Aristocrats. Did the issue period end already? Has anyone seen a copy at the Brea Mall Disney store (or anywhere else recently)?

(2) Check Tower Records. For ARISTOCATS.

(3) Price Club has Aristocats around \$16 I think. Fedco might, too.

While common at The Castle, such highly local behavior would be entirely inappropriate for other Net venues such as Usenet's rec.arts.disney newsgroups.

\section{Locality of Action}

As with reference and focus, activity at The Castle is also highly localized. This is both the most obvious and most influential affordance of being geographically localized. The participants of The Castle make a very conscious effort to blend their virtual and real worlds. They do this most commonly through informal meetings at Disneyland and at special Castle sponsored events.

The sysops organize formal events, such as special park gatherings (especially for openings and closings of attractions, shows, or parades), history tours of the park, and opening night screenings and parties for Disney films. All of these are significant productions, but none compares with The Castle's annual day at the park, King's Challenge. The annual days are elaborate all day competitive events, which are exceedingly popular and very well attended (with nearly sixty attendees in its third year).

King's Challenge is the best opportunity to meet participants face to face. One user wrote:

It was good to put faces to your names, even if you all looked nothing

like I expected.

These real life gatherings are an essential component of this online community, facilitated by the local nature of its membership. In addition to these formal events are informal events sponsored by the participants of The Castle. Some of the informal real-life events have included holiday parties at the park, such as Halloween or a New Year's Eve celebration at the adjoining Disneyland Hotel. Others include the formation of teams from The Castle to compete in cast member competitions such as the annual charity $5 \mathrm{~K}$ race. These face-to-face activities are common to many geographically distributed online communities (i.e. the annual summer picnic for the WELL as described by Rheingold, 1993), although the Castle likely has a higher percentage of its core participants routinely attend.

Unusually, geographical localization leads to day-to-day real-life interaction as well. One of the most common threads in The Courtyard consists of a participant's open, public invitation to meet others at the park. Frequently, individuals will post the times they are visiting and invite anyone to join them or to arrange a meeting place and time. One such example from a new person:

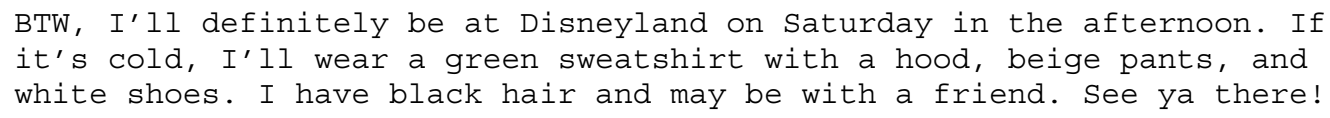


In fact, these invitations are so common it caused one relatively new user to question whether the community met at the park on a regular, weekly basis.

Cast members, as well, will post their work schedule and break times, inviting others to stop by while they are on or off duty. In the following message an employee responds to another user:

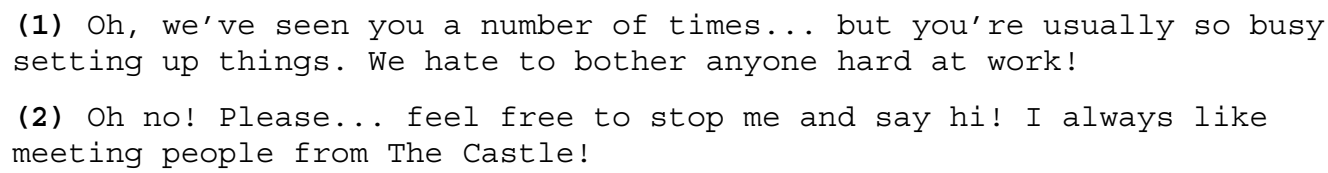

This type interaction between participants, one of whom is a Disneyland employee, is common. A restaurant employee writes:

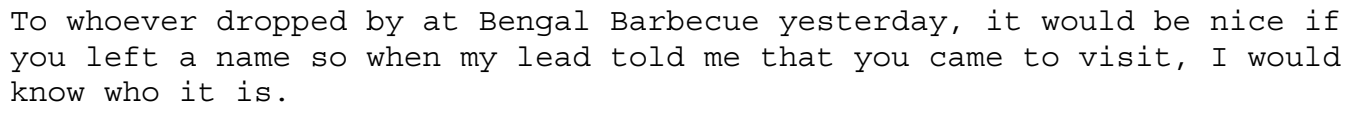

In summary, the various forms of locality provide important contexts to the community's online interactions. In addition, being local provides an ability for Castle participants, both cast members and fans, to interact in person after having met online. The next section describes how The Castle's centrality and its locality interact to create an even more powerful incentive for all participants.

\section{Centrality and Locality Together: Hanging Out Backstage}

In the online community of The Castle, the interplay of interest networks and geographic localization yields an additive effect. The combination of locality and centrality allows participants to become part of the Disneyland scene, although a small and sometimes vicarious part. This is a great incentive and attraction for The Castle's participants.

Many enthusiasts desire to become part of "the scene" of their fancy; that is, to vicariously enter the world that is the focus of their fandom (Lewis, 1992). It is likely that all social worlds are stratified, with some participants more closely identifying with the norms, rituals, and understandings. Becker (1982) suggested such stratification in his examination of high and folk art. Similarly, Fox (1987) argued that punk rockers were stratified into hardcore, softcore, preppie punks, and spectators.

In fandom and other social worlds, one may not easily become a creator of the entertainment or art form idealized. However, enthusiasts attempt to gain limited access by hanging out with others more connected into the social world. It is a well-known social phenomenon with many names - for example, opera buffs (Martorella, 1992), stage-door johnnies, fireman wannabes, trekkies and Babylon 5 fans (Jindra, 1994; Wexelblat, 1997), college football boosters, soccer fans (Redhead, 1993; Murphy, Williams, and Dunning, 1990) and even rock groupies (Barlow, 1995; Watson, 1997) - people who hang out at the fringes with a feeling of deep participation.

The Castle offers a similar opportunity to Disney enthusiasts. They desire to become part of the Disney spirit. The cache of Disney insiders at The Castle is a sizeable attractor for these Disney enthusiasts; through these relationships the degree of their involvement increases - allowing them to go backstage (Goffman, 1961; Meyrowitz, 1985) to glimpse performances that the general public is not allowed to view.

Aware of the unique opportunities afforded by The Castle, one user remarked,

"if on this board a lot of the employees didn't sign on, the nature of the board would be very different. I don't think this particular board would have survived in Decatur, GA.... I think that [being local] really lends a specific flavor that you are not going to find anywhere else." 
As has been described throughout this paper, the message logs are replete with Castle participants both wanting to meet employees at the park as well as to gain knowledge that is not readily available outside Disney.

The following conversation excerpt is a classic example from The Castle of the desire to go backstage. A moderately new participant posts a casual introduction to all participants. He requests insider information, especially from eavesdropping:

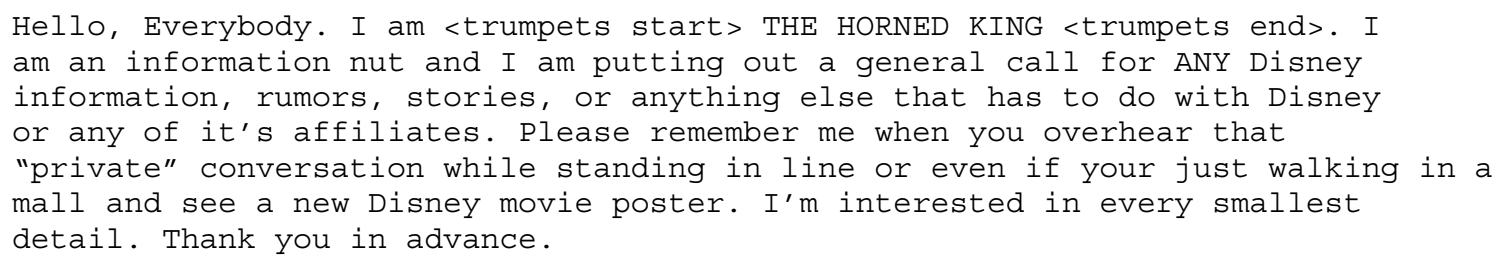

A low-level employee, currently working at a retail outlet, who appears to be an acquaintance from elsewhere, is provided with an opportunity to gossip:

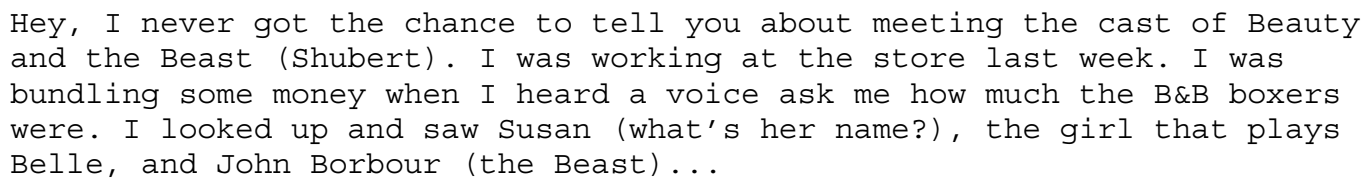

Other low-level employees explain events at Disneyland that would otherwise be unknowable to outsiders. One Castle participant noted that there were a number of celebrities when he visited Disneyland. A cast member responded:

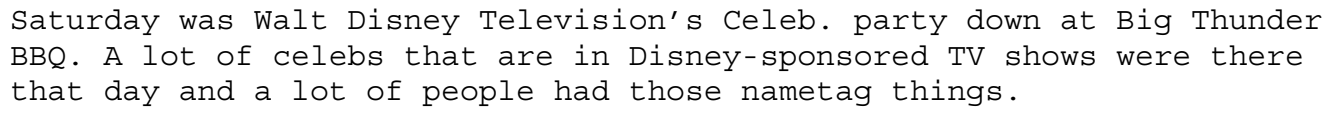

The Castle's message logs are full of similar tidbits. Still, other employees provide backstage context. In the following message, a relatively low-level employee discusses possible enhancements to a Disneyland attraction. This was part of an extended thread discussing the history of that show:

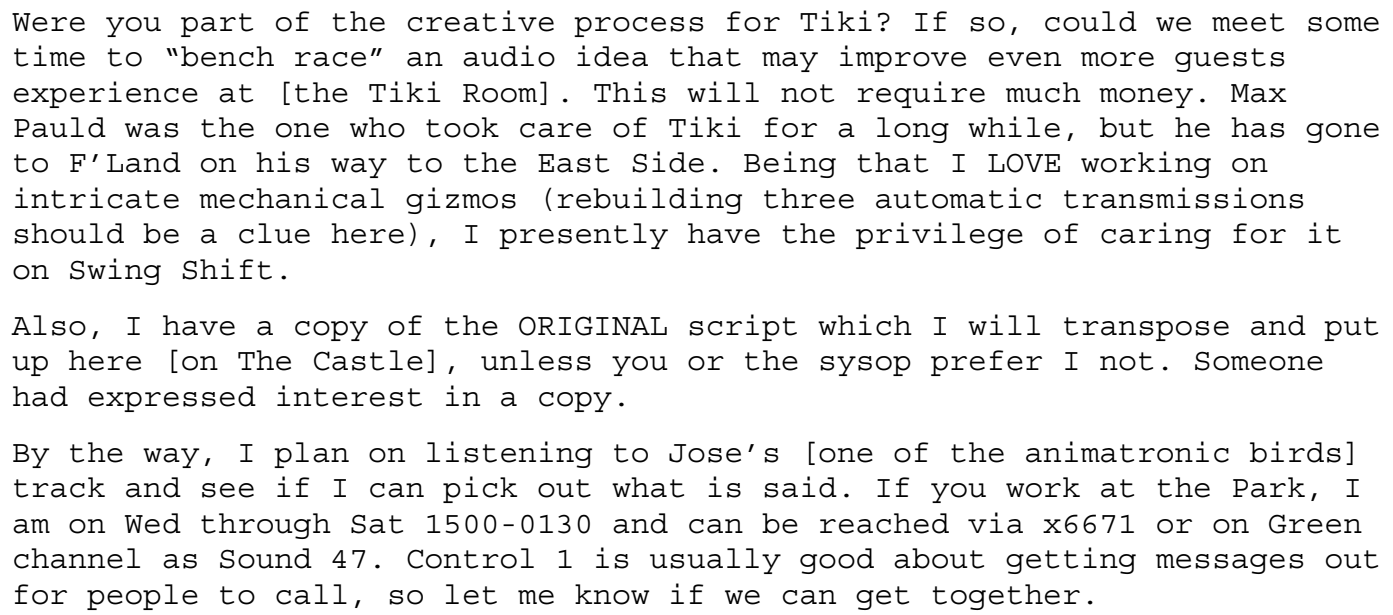

Indeed, many of the cast members treated with reverence by other Castle participants are low-level Disneyland employees themselves. Specifically, three core participants most frequently involved with park discussions include a seasonal employee, a maintenance worker, and a soundstage technician.

Backstage knowledge and experience provides both a social reciprocity and dual incentives for two important groups at The Castle - Disney employees and Disney fans. (This is parallel to the dual incentives for patients and medical staff in Preece, 1998, as well as help seekers and help providers in 
Ackerman and Palen, 1996.) It offers Disney employees additional status, a status perhaps not accorded while at work: If nothing else, they are insiders. This gives them a reason to return to The Castle and to actively participate in the community. For fans, The Castle is a place to meet and befriend inside people and, equally important, to gain backstage knowledge. Considerable status and legitimization within fandom comes from who you know or with whom you have been seen; being able to say you know one of the designers for the new Main Street parade or being seen entering the park for free through the employee entrance are significant experiences for fans.

The combination of locality and centrality, then, provides extra incentives for the participants of The Castle. As with opera, sports, rock, and a myriad of other fandoms, The Castle satisfies Disney and Disneyland enthusiasts' desire to become a part of the Disney scene.

We believe, although we cannot say with certainty, that locality and centrality alone would provide significant incentives to Castle participants. However, the combination of the two provides many additional affective overtones to the community interactions. Any opportunity for such a combination in an online community should be encouraged.

\section{CONCLUSION}

In this paper, we went back in time to an earlier community technology to examine how to create viable small-scale community spaces. We found a social mechanism that appears to have been lost in the Web era. Here, we have presented a field study of an online community, focused on Disney and Disneyland, that had, in our belief, important social characteristics. As with many current CMCs, the community focused on fandom. This intense focus allowed The Castle to function as a collecting point for people interested in Disney and Disneyland - that is, the focus led to a centrality for the community in the participants' interest networks. People could find similar enthusiasts and even people with specialized or insider knowledge. Yet, unlike current CMCs, because of the cost structure of dialup access (an accidental side-effect of the technology), participants were overwhelmingly local geographically. This had useful consequences for staying focused (locality of focus), how people made sense of their world and their interactions (locality of reference), and in creating new interactions (locality of action).

Most importantly, however, putting the two together - centrality and locality - created a powerful social dynamic. This dynamic is not new; it exists in many current social forms, with people who want be (in Goffman's term) "backstage" with football players, movie stars, or opera singers. The Castle was the place to be for Disneyland enthusiasts. The Castle presented an opportunity for fans to hang out with insiders and for low-level insiders to gain status by showing off their insider knowledge to fans. We have also suggested, although we have limited data, that this was a social mechanism by which Disney fans could validate their interest and more tightly integrate into the enthusiast's social world (Strauss, 1991; Fox, 1987).

The combination of locality and centrality created a powerful social mechanism by which the community could maintain and reinforce membership in the face of technologically superior competition. As with any field study, there are challenges in generalizing from a single site. Nonetheless, given the theoretical generalizability of locality and centrality as dimensions of social maintenance over time, we believe that this combination could be quite useful in webspaces and webboards as well.

Of course, The Castle did eventually fail as an online community: It vanished slowly in 1998 and 1999, although well into the Web Era. There were many simultaneous reasons for its demise. Two of the three sysops of The Castle, the social hubs of the community and the technical maintainer of the system, had a child and had much less time to devote. In addition, the advent and excitement of the Web made a text-based dialup space less exciting and fashionable, which may have led to a social meltdown (where people do not come to the space because they do not believe that others will be there (Ackerman and Starr, 1996)). In addition, The Castle became technically obsolete with a highly limited user interface, aging user clients, obsolete access mechanisms, restricted interconnectivity with other messaging systems, and limited expandability. The owners of the system, in fact, believed that The Castle needed to move to a 
Web-based infrastructure. Regardless of whether this belief was based on an objective assessment of the technology itself or was based on media hype, constructing such a Web-based infrastructure required vastly more financial and technical resources than they had available.

Such an infrastructure is still difficult to create and bring into a small-scale web site. There are commercial products and some open source efforts to create entire spaces (e.g., webboard). However, to create the nightclubs, bars, taverns, and diners of the Internet - to maintain the Net against being only large-scale commercial spaces - we will have to find the technical and social mechanisms by which these spaces can be easily created, maintained, and enhanced.

\section{Notes}

[1] Disneyland is the original Disney amusement park located in Anaheim, California, USA.

[2] Based on the work of Kollock and Smith (1996), Nonnecke describes lurkers as the free-riders in an online community, specifically "noncontributing, resource-taking members." (2000)

[3] These forms of creative participation are not unique to online fan communities, as noted in Jenkins (1992), but are greatly enhanced by the media and audience provided on the Net.

[4] Each message at The Castle contains standard header information as is commonly found in e-mail or Usenet postings, with some additional fields for threading and notification. The header provided in the first message of this exchange is typical. To conserve space and improve readability, we omit the headers for all later examples. All names and identifiers have been changed in all data presented here to allow anonymity for the users and their characters. We have corrected spelling and grammar, and reformatted messages for readability.

[5] We were able to collect the complete current archive, with some sections dating back to the founding of the board in 1993. While these data were occasionally used (e.g., as background for interpreting current messages), they are not presented here. The first author remained an active participant on the board until its demise in 1999.

[6] As cited from the new user registration, "to remain an active user here, you must call back within 30 days. After that, you will need to call at least once every 90 days or your account will be deleted and you will need to complete the registration process again." Their strict enforcement of this policy stood in stark contract with the loose membership standards of most other dial-up bulletin board systems.

[7] Based on posting behavior alone there were 28 core participants. There were ten other participants who were valued, long-term participants who posted infrequently but routinely lurked.

[8] For example, there have been at least thirteen direct variations on "Indiana Jones," the popular action hero and central character in a popular new attraction at Disneyland. A month long thread revolved around a case of mistaken identity between two "Indiana Jones" handles.

[9] The cultural norm of strict adherence to theme is not restricted only to the conferences but is mirrored throughout all aspects of The Castle.

[10] Administration of the board is handled by a trio of sysops and supported by volunteers from the core participants.

[11] While general demographic information for the board was not available, face-to-face interaction by the first author with at least 55 participants confirmed suspicions that the community was significantly more mature than the standard, stereotypically teenage, dial-up bulletin board system.

[12] As mentioned previously, explicit demographic information for the population at The Castle was not available. However, an approximation can be based on the boundary where the local phone company deems a call to The Castle to be a local versus a toll call. A twelve mile radius surrounding the board is considered local (free), and a twenty mile radius is considered "Local+" (heavily discounted toll). This 20 
mile boundary is borne out in the log and interview data; nearly all participants live in Orange County or southern Los Angeles. This is also validated by one of the sysops, who commented, "Most people here are from the immediate area, although we do occasionally get visitors from out of state. Basically, it comes down to a monetary issue. If the call is free, then there's more incentive to call. If it costs money, then you'll probably try to get your information elsewhere."

[13] This is precisely the opposite effect of glocalization, "a global outlook adapted to local conditions," as coined by Hampton and Wellman (2001).

\section{References}

Ackerman, Mark S., and Palen, Leysia (1996), “The Zephyr Help Instance: Promoting Ongoing Activity in a CSCW System", Proceedings of the ACM Conference on Human Factors in Computing Systems (CHI'96), pp. 268-275.

Ackerman, Mark S., and Star, Brian (1996), "Social Activity Indicators for Groupware", IEEE Computer (29:6), pp. 37-44.

Barlow, John Perry (1995), “Cyberhood vs. Neighborhood: Are Computer Networks Real Communities? (are Neighborhoods?)", Utne Reader, March-April, pp. 50-75.

Baym, Nancy K. (1997), "Interpreting Soap Operas and Creating Community: Inside an Electronic Fan Culture", in Kiesler, Sara ed. Culture of the Internet, Lawrence Erlbaum Associates, Mahwah, NJ, pp. 103-120.

Becker, Howard S. (1982), Art Worlds, University of California Press, Los Angeles.

Carroll, John M. and Rosson, Mary B. (1996), "Developing the Blacksburg Electronic Village", Communications of the ACM (39:12), pp. 69-74.

Cohill, Andrew M. and Kavanaugh, Andrea L., eds. (2000), Community Networks: Lessons From Blacksburg, Virginia, Artech House.

Correll, Shelley (1995), "The Ethnography of an Electronic Bar: The Lesbian Café", Journal of Contemporary Ethnography (24:3), pp. 270-298.

Cressey, Paul G. (1932), The Taxi-Dance Hall: A Sociological Study in Commercialized Recreation and City Life, University of Chicago Press, Chicago.

Elmer-Dewitt, Philip (1993), "First Nation in Cyberspace", Time. December 6 ${ }^{\text {th }}$, pp. 62-64.

Farrington, C. and Pine, E. (1992), "Community Memory: A Case Study in Community Communication", in Agre, P. and Schuler, D., eds. (1997), Reinventing Technology, Rediscovering Community: Critical Studies in Computing as a Social Practice, Ablex Publishing, Norwood, NJ.

Fox, Kathryn Joan (1987), "Real Punks and Pretenders: The Social Organization of a Counterculture", Journal of Contemporary Ethnography (16:3), pp. 344-370.

Goffman, Erving (1961), The Presentation of Self in Everyday Life, Anchor-Doubleday, New York.

Hampton, Keith (2001), "Living the Wired Life in the Wired Suburb: Netville, Glocalization and Civil Society", Dissertation, University of Toronto.

Jenkins, Henry (1992), Textual Poachers: Television Fans and Participatory Culture, Routledge, New York.

Jindra, Michael (1994), "Star Trek Fandom as a Religious Phenomenon," Sociology of Religion (55:1), p. 27. 
Kollock, Peter and Smith, Marc (1996), "Managing the Virtual Commons: Cooperation and Conflict in Computer Communities", in S. Herring, ed., Proceedings of Computer-Mediated Communication: Linguistic, Social and Cross-Cultural Perspectives, John Benjamins, Amsterdam, pp. 109-128.

Lewis, Lisa A. ed. (1992), The Adoring Audience: Fan Culture and Popular Media, Routledge, New York.

Lofland, John and Lofland, Lyn H. (1995), Analyzing Social Settings: A Guide to Qualitative Observation and Analysis (Third Edition), Wadsworth Publishing, Belmont, CA.

Maines, David R. (1991), Social Organization and Social Process: Essays in Honor of Anselm Strauss, A. de Gruyter, New York.

Martorella, Rosanne (1982), The Sociology of Opera, Praeger, New York.

Meyrowitz, Joshua (1985), No Sense of Place: The Impact of Electronic Media on Social Behavior, Oxford University Press, New York.

Murphy, Patrick, Williams, John, and Dunning, Eric (1990), Football on Trial: Spectator Violence and Development in the Football World, Routledge, New York.

Myers, David (1987), “Anonymity is Part of the Magic: Individual Manipulation of Computer-Mediated Communication Contexts", Qualitative Sociology (10:3), pp. 251-266.

Neff, R. (1995), “The Cleveland Free-Net”, in Schuler, Douglas (1996), New Community Networks:

Wired for Change, Addison-Wesley Publishing Company, Menlo Park, CA.

Nickerson, Raymond S. (1994), "Electronic Bulletin Boards: A Case Study of Computer-Mediated Communication", Interacting with Computers (6:2), pp. 117-134.

Nonnecke, Blair and Preece, Jenny (2000), "Lurker Demographics: Counting the Silent”, Proceedings of the ACM Conference on Human Factors in Computing Systems (CHI'00), pp. 73-80.

Orlikowski, Wanda J. (1992), "Learning from Notes: Organizational Issues in Groupware Implementation", Proceedings of the ACM Conference on Computer Supported Cooperative Work (CSCW'92), pp. 362-369.

Preece, Jenny (2000), Online Communities: Designing Usability, Supporting Sociability, John Wiley \& Sons, New York.

Preece, Jenny (1998), "Empathic Communities: Reaching Out Across the Web”, Interactions, pp. 32-43.

Redhead, Steve, ed. (1993), The Passion and the Fashion: Football Fandom in the New Europe, Avebury Publishers, Aldershot, United Kingdom.

Rickard, Jack (1993), “Home-Grown BB\$”, Wired, September-October, pp. 42-45.

Rheingold, Howard (1993), The Virtual Community: Homesteading on the Electronic Frontier, Harper Collins Publishers, New York.

Sproull, Lee and Kiesler, Sara (1991), Connections, MIT Press, Cambridge, MA.

Schuler, Douglas (1996), New Community Networks: Wired for Change, Addison-Wesley, Menlo Park, CA.

Schmitz, Joseph (1997), "Structural Relations, Electronic Media and Social Change: The Public Electronic Network and the Homeless", in Jones, Steven G., ed. Virtual Culture: Identity and Communication in Cybersociety, Sage Publications, Thousand Oaks, CA, pp. 80-101.

Strauss, Anselm (1991), Creating Sociological Awareness: Collective Images and Symbolic Representations, Transaction, New Brunswick. 
Strauss, Anselm and Corbin, Juliet (1990), Basics of Qualitative Research: Grounded Theory Procedures and Techniques, Sage Publications, Thousand Oaks, CA.

Strauss, Anselm (1987), Qualitative Analysis for Social Scientists, Cambridge University Press, New York.

Turkle, Sherry (1995), Life on the Screen: Identity in the Age of the Internet, Simon \& Schuster, New York.

Van Tassel, Joan (1994), “Yakety-Yak, Do Talk Back!” Wired, January, pp. 78-80.

Watson, Nessim (1997), "Why We Argue About Virtual Community: A Case Study of the Phish.Net Fan Community", in Jones, Steven G., ed., Virtual Culture: Identity and Communication in Cybersociety, Sage Publications, Thousand Oaks, CA, pp. 102-132.

Wexelblat, Alan (1997), "An Auteur in the Age of the Internet: JMS, Babylon 5, and the Net", unpublished manuscript available at http://wex.www.media.mit.edu/people/wex/FMS/Top.html 